\title{
Tracking Cross-Disciplinary Information Use by Author Affiliation: Demonstration of a Method
}

\section{Lina Ortega and Karen Antell}

\begin{abstract}
In this paper, we report the results of a bibliometric study in which we track cross-disciplinary citation behavior in the sciences. We hypothesize that cross-disciplinary citation in the sciences increased over the time period 1985-2000. Unlike most previous studies in this area, we assign discipline to a paper by its first author's affiliation, and we hypothesize that assigning papers to disciplines based on first-author affiliation would yield results consistent with previous findings on cross-disciplinary citation rates in the sciences. Using the output of scientists in Biological Sciences, Chemistry, and Physics departments at 12 large research universities in 1985, 1990, 1995, and 2000 as our data set, we measure the crossdisciplinary citation rates of each discipline and compare our results to the findings of previous studies in this area.
\end{abstract}

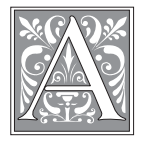

ccording to Rustom Roy, interdisciplinarity was "born" in 1960 when the sciences, which for a century had been fragmenting into smaller, specialized sub-fields, responded to the post-Sputnik call for a "New Frontier" in science and education. Solving the "mission-critical" problems of society - in the environment, medicine, energy, and space research - required science to cross disciplinary boundaries and even to forge new disciplines in the interstitial areas between disciplines. ${ }^{1}$

The birth of interdisciplinarity has led to new patterns in the dissemination and use of scientific information, because scientists doing interdisciplinary research need to use information from outside their "home" discipline. In an attempt to serve scientists' information needs better, librarians and information scientists have measured and tracked these new patterns in numerous ways, many of which involve the collection and analysis of citation data. Citations constitute convenient "counters" because they are generally assumed to reflect the use of information.

To study these patterns, researchers must have some way of assigning a paper to a certain discipline, in order to determine whether citations to it fall within the same discipline or a different discipline. Most studies on this topic assign discipline by subject or "category." Some

Lina Ortega is Chemistry \& Mathematics Librarian in Chemistry-Mathematics Library and Karen Antell is Head of Reference and Outreach Services at University of Oklahoma Libraries; e-mail: lortega@ou.edu and kantell@ou.edu, respectively. The authors gratefully acknowledge Christopher Dalton and Lacey Downs for research assistance with this project. 
researchers assign discipline based on the descriptors or subject headings assigned by an indexing service to the paper itself. Others assign a paper's discipline by the Library of Congress (LC) classification or the Institute for Scientific Information (ISI) category of the journal in which the paper appears.

This is a logical way to assign discipline, but as numerous researchers ${ }^{2}$ have noted, it is fraught with ambiguity: "A serious shortcoming of bibliometric studies based on [ISI data] is the lack of a universally applicable subject classification scheme [for] individual papers." ${ }^{3}$ In this paper, we present another way to "assign" a discipline to a paper, using the "author affiliation" feature of ISI's Web of Science. We chose this method to avoid the many ambiguities that result from assigning discipline by subject. Authors who have used ISI's journal categories to assign discipline have had to account somehow for the fact that ISI "multi-assigns" journals - that is, one journal can be listed in several different categories. Fernanda Morillo, María Bordons, and Isabel Gómez (2003) found that, on average, " $53 \%$ of journals within each [ISI] category were multi-assigned." ${ }^{4}$ The same is true for the use of subject headings, at both the journal and the article level: multiple subject headings means that it can be difficult to unambiguously assign a discipline to a particular paper. In addition, ISI's categories vary greatly, and rather arbitrarily, by size and scope. Some categories encompass relatively broad categories of discipline, such as "Chemistry, Physical," which includes 101 journals. Other categories are much narrower: "Andrology," with 5 titles, covers a much smaller subfield within a discipline. Moreover, the ISI categories themselves are often interdisciplinary. "Geriatrics and Gerontology," with 27 journal titles, includes many titles from each of the disciplines traditionally conceived as Biological Sciences and Medicine, as well as some from disciplines outside the sciences, such as Psychology. In fact, some titles are cross-listed in categories in the Social Sciences. The interdisciplinarity of the ISI subject categories thus confounds the use of these categories to assign discipline for the purposes of measuring interdisciplinarity.

Our method, on the other hand, is unambiguous: we assign each paper a discipline based on its first author's departmental affiliation. Papers whose first authors are affiliated with chemistry departments are assigned to Chemistry; papers whose first authors are affiliated with zoology departments are assigned to Biological Sciences, and so forth. In addition, by dividing science into only three broad disciplines-Chemistry, Physics (including Astronomy), and the Biological Sciences - our method sets a high bar for "interdisciplinarity." That is, a paper by an organic chemist citing a paper by a physical chemist does not "count" as a cross-disciplinary citation according to our scheme, because both papers are assigned to Chemistry. We use broad disciplines so that our measurement reflects true cross-disciplinary information use, not merely the use of information by scientists in separate but related subdisciplines.

This study's use of author affiliation to assign discipline is not entirely new. Sydney J. Pierce uses author affiliation to assign discipline in a study of "boundary-crossing" that measures how often authors from one discipline publish in another discipline's journals. ${ }^{5}$ In a study of interdisciplinary collaboration, Liwen Qiu assigns discipline by authors' departmental affiliations. ${ }^{6}$ Joachim Schummer assigns discipline by author affiliation in a study of the interdisciplinary nature of nanotechnology journals. ${ }^{7}$ However, author affiliation has not been used to assign discipline to papers in any previous study of interdisciplinarity across the broad fields of science.

Our study measures cross-disciplinary citation over time in the broad science disciplines: Chemistry, Physics, and the Biological Sciences. We hypothesized 
that cross-disciplinary citation in the sciences had increased over the time period 1985-2000 because, by many counts, interdisciplinary research appears to be increasing. According to John W. Houghton, Colin Steele, and Margaret Henty, "There is a shift away from pure/basic research towards more applied and developmental activities, and a decline in the share of expenditure on 'non-oriented' research with strong increases in the more interdisciplinary, problem oriented fields." 8 Today, major funding sources, such as NSF, often give preference to applied research projects with a demonstrated "broader impact" to society than pure research. ${ }^{9}$ According to the most recent NSF Science $\mathcal{E}$ Engineering Indicators, "Cutting-edge science in many fields increasingly involves a broad range of knowledge, perspectives, and techniques that extend beyond a given discipline or institution."10 On a related note, the Science \& Engineering Indicators report a steadily decreasing proportion of researchers involved in pure or basic research, ${ }^{11}$ indicating a corresponding increase in the proportion of applied research, which is more likely to be interdisciplinary in nature. In addition, the proliferation of research institutes with names such as "Interdisciplinary Center for Biotechnology Research" over the last 15 years is an informal but highly visible indicator of the increasing significance of interdisciplinary research in the sciences. One very rough measure of this, a count of citations in Compendex (performed in October 2005), shows 106 citations in 2005 by authors whose affiliations include the phrase "interdisciplinary center," "interdisciplinary centre," "center for interdisciplinary," or "centre for interdisciplinary." This count is indeed an unscientific way to gauge the increase in the number of interdisciplinary centers, but it does provide a quick idea of the magnitude of change: by comparison, for 2000, this count turned up only 24 citations; and, for 1995 and 1990, the counts were 13 and 0, respectively.
In addition to hypothesizing that cross-disciplinary citation activity had increased from 1985 to 2000, we also hypothesized that assigning papers to disciplines based on first-author affiliation would yield results consistent with previous findings on cross-disciplinary citation rates in the sciences. We chose first-author affiliation as an alternative to ISI category both because author affiliation is readily available in Web of Science, the most comprehensive and most commonly used citation analysis tool, and because it overcomes the ambiguity of assigning discipline based on ISI category. To measure the reliability of the author-affiliation method, we compared our results to the results of other studies of interdisciplinarity in the sciences to gauge how well our method corroborates previous findings.

\section{Literature Review}

The literature on using citation analysis to measure interdisciplinarity is both vast and diverse. Some studies focus on the interdisciplinary nature of a single field ${ }^{12}$ others on methods for creating core journal lists in interdisciplinary fields, ${ }^{13}$ and still others on producing "maps" of the interrelatedness of multiple fields. ${ }^{14}$ However, here we will focus on studies that are most comparable to ours: studies that use citation analysis to measure and compare the amount of interdisciplinary information usage of several different disciplines.

\section{Seminal Works on the Use of Citation Analysis to Measure Interdisciplinarity}

Two papers stand out as being seminal works in this area. Based on the 1965 output of academic literature in the UK, Penelope Earle and Brian Vickery's 1969 study covers most academic disciplines and, using Dewey classification to assign discipline, measures the extent to which disciplines cite themselves and cite other disciplines. ${ }^{15}$ The sheer amount of data gathered and analyzed in this study makes it remarkably useful as a bench- 
mark for other researchers. A. L. Porter and D. E. Chubin's 1985 paper introduces the indicator known as "Citations Outside Category" (COC), ${ }^{16}$ which subsequently has been employed (and often modified) by many other researchers on interdisciplinarity. COC relies on the journal subject categories established by ISI in its Science Citation Index, Social Sciences Citation Index, and Journal Citation Reports, all of which are now accessible through ISI's Web of Science database. COC has the advantage of being fairly simple to understand and to use. It is an excellent tool for obtaining a rough and ready estimate of the interdisciplinarity of a given set of papers. However, as many researchers have noted, ${ }^{17}$ and as discussed above, COC also has the potential to be somewhat ambiguous and arbitrary, especially when, as is often the case, it is based on ISI categories.

\section{Other Works Employing “Citation Outside Category" or Similar Measures}

Porter and Chubin's COC measure has been applied successfully, and in some cases modified, by numerous researchers in a variety of studies of interdisciplinarity. Jin M. Choi uses COC to measure the "centripetal" and "centrifugal" tendencies of the anthropological literaturethat is, in what proportions the literature relies on other anthropological literature (centripetal) and on literature outside the discipline (centrifugal). In analyzing citations, Choi assigns discipline by LC classification, a scheme that avoids the ambiguity of ISI categories. ${ }^{18}$

Morillo et al. (2001) use the chemical literature to compare COC with two other measures of interdisciplinarity - analysis of ISI multiassignation of journals and analysis of multiassignation of documents in Chemical Abstracts. They find similar results from all three measures, but they note that this convergence might not hold for other disciplines and that the ISI multiassignation of journals is a less sensitive measure than the other two. ${ }^{19}$

Pierce studies a more direct form of interdisciplinary communication, "bound- ary crossing," which occurs when authors publish outside their own fields. As in our study, she uses author affiliation to assign discipline, noting that "academic departments [and] graduate programs .... are organized along disciplinary lines." ${ }^{20}$ Focusing on sociology and political science, Pierce finds, contrary to assumptions, that boundary-crossing articles are cited more frequently by journals in disciplines outside the author's disciplinary affiliation than non-boundary-crossing articles.

$\mathrm{Ed} \mathrm{J}$. Rinia et al. analyze a huge data set of 643,000 citations from Science Citation Index - the complete set of citations as of 1999. This study applies a measure similar to COC to all scientific disciplines and their interrelations, assigning discipline by ISI journal category while noting the limitations of assigning discipline in this way and calling for investigations into other methods of assigning discipline. Their results quantify the degree of self-citation of each scientific discipline as well as the degree and the pattern of citation outside of discipline. ${ }^{21}$ Similarly, Schummer also calls for "a method independent from journal classification." 22 He uses coauthor affiliation analysis to determine the interrelatedness of subject literatures in nanotechnology, concluding that, although many disciplines are seeing an increase in the number of articles they publish on nanotechnology, little interdisciplinary communication is taking place.

The 1998 NSF Science E Engineering Indicators includes a table of the distribution of citations across both broad and narrower fields for articles published in the United States in 1994 and 1995 that cited other articles published in 1990 through 1993. ISI categories were used to assign discipline to articles, and, for that time period, cross-disciplinary citation rates were higher for Biology and Engineering than for Physics and the Earth Sciences. ${ }^{23}$

Thed van Leeuwen and Robert Tijssen use ISI categories to assign discipline and measure cross-disciplinary citation $(\mathrm{CDC})$, an indicator that is virtually 
identical to COC. This study covers most scientific disciplines and measures not only the amount of interdisciplinarity of each field but also the change in interdisciplinarity over the time period 1985-1995. The authors find great variability among the disciplines with respect to their level of interdisciplinarity (ranging from 14\% for astronomy and astrophysics to $97 \%$ for medical informatics) but detect little change in interdisciplinarity for most fields during this decade. ${ }^{24}$

\section{Significant Studies That Use Other Mea- sures of Interdisciplinarity}

A few recent studies take novel approaches to assigning discipline and measuring interdisciplinarity. W. Glänzel et al. address the "problem" of articles in multidisciplinary journals, such as Science, Nature, and the Proceedings of the National Academy of Sciences, by assigning a paper's discipline by its citations rather than by its journal category. The authors test their method by applying it to several discipline-specific journals and comparing the results with previous results using more traditional methods. They find a high rate of convergence between methods, indicating that their method is valid and useful for analyzing articles in multidisciplinary journals. ${ }^{25}$

Morillo et al. (2003) develop an indicator of interdisciplinarity based on ISI's multiassignation of categories - that is, they count as more interdisciplinary those journals that are assigned to multiple categories by ISI. In effect, this method turns the ambiguity of ISI categories into another tool for measuring interdisciplinarity. ${ }^{26}$

Qiu, like Pierce, uses author affiliation to assign discipline, but studies crossdisciplinary collaboration rather than boundary-crossing publication or citation outside discipline. In the field of library and information science between 1972 and 1991, Qiu finds that the percentage of interdisciplinarily collaborative articles, although low ( $2.7 \%$ overall), is increasing significantly. ${ }^{27}$

\section{Citation Analysis for Collection Develop- ment and Management}

Julie Hurd's work is a prime example of the use of interdisciplinary measures to guide collection development. She typically gathers citation figures using local samples, so her findings yield data that represent information use at a particular institution, and she uses her findings to make recommendations for collection development. She has published several studies in which she employed COC to measure interdisciplinarity in the sciences. In one study (1992), Hurd investigates the literature used by chemists at one institution and finds that 49 percent of the literature they cited in their papers came from outside the discipline of Chemistry. In this study, Hurd assigns discipline to the cited papers by author affiliation and to the citing papers using categories from Ulrich's International Periodicals Directory. Her results are interesting, but the fact that she assigns discipline differently to the citing and cited papers introduces a degree of uncertainty about whether the results would be different if discipline had been assigned the same way to both sets of articles. As she notes, 40 percent of the citing papers (by the chemists) were actually published in journals that Ulrich's does not classify as chemistry journals, so her results might have been different if she had assigned discipline in the same way to both the citing and cited papers. ${ }^{28}$

Hurd's 1999 paper on the literature used by molecular biologists is similar in its treatment. She examines the output of papers from a group of molecular biologists, again assigning their discipline by departmental affiliation, and investigates the disciplines of the literature they cite, again assigning discipline to the cited literature using Ulrich's journal classification. She finds that 59 percent of the cited literature is classed in biology, with the remaining literature coming almost exclusively from the classes of Medicine and "General Science" (covering multidisciplinary periodicals such as Science, Nature, and Proceedings of the National Academy of Sciences). ${ }^{29}$ 


\section{Methodology}

We used ISI's Web of Science database to locate journal articles written by authors affiliated with biological, chemical, or physical science departments in the Big 12 universities (see table 1 ) and published in the years 1985, 1990, 1995, or 2000. We chose this set of institutions because it would provide data that was "local" (it includes our institution, the University of Oklahoma) while drawing on a broader sample than just our own institution. The Big 12 universities are often considered by university administrators to be the University of Oklahoma's "peer class" for gauging the university's development with regard to research funding, endowment sizes, faculty salaries, library holdings, and so forth. As a "peer class" for the University of Oklahoma, the Big 12 is apt because all of its institutions are large, publicly funded, comprehensive research universities, and 11 of the 12 are members of the Association of Research Libraries.

Science departments were identified by examining departmental listings on each institution's Web page and then categorizing them into Biological Sciences, Chemistry, or Physics. For example, a Department of Ecology and Evolutionary Biology was categorized as Biological Sciences, and a Department of Astrophysical and Planetary Sciences was categorized as Physics. A list of articles was retrieved for the selected departments at each location for each of the four years. Data on articles were gathered for five-year increments ending with the year 2000 to allow ample time for the "three-year citation peak" to have occurred. ${ }^{30}$

In order to work with a manageable set of articles, we used a random sample generator in SPSS to select 50 articles from each of the three disciplines and each of the four years that were investigated. This resulted in 12 "discipline-year" sets of 50 articles each. Next, for each disciplineyear set, a list of citations to the articles was compiled using Web of Science. Thus, for each of the 12 discipline-years, we

\begin{tabular}{|l|}
\multicolumn{1}{|c|}{ TABLE 1 } \\
Big 12 Universities \\
\hline \hline Iowa State University \\
Kansas State University \\
Oklahoma State University, Stillwater \\
Texas A\&M University, College Station \\
Texas Tech University \\
University of Colorado, Boulder \\
University of Iowa \\
University of Kansas \\
University of Missouri, Columbia \\
University of Nebraska, Lincoln \\
University of Oklahoma, Norman \\
University of Texas, Austin \\
\hline
\end{tabular}

ended up with two data sets that formed a discipline-year pair: the list of fifty original sampled articles and the (much longer) list of their citing articles. The 12 lists of citing articles ranged in length from 277 citations (to Biological Sciences articles published in 2000) to 1,374 citations (to Physics articles published in 1990).

Next, the departmental affiliation for the first author of each citing article was identified in order to assign a discipline-Biological Sciences, Chemistry, Physics, or Other-to the paper. This enabled us to calculate the percentage of cross-disciplinary citations (CDCs). We counted a citation as "cross-disciplinary" if its first author's affiliation was from a different discipline from that of the article it cited. We then analyzed and looked for patterns in the differences in CDC rates among the four years and among the three disciplines.

To help us discern additional patterns, we then did further analysis to determine the composition of the "Other" category. Again, we grouped the citations into disciplines according to their first author's affiliation, but this time we included the categories Engineering, Medicine, General Science, and "Other." General Science comprises authors affiliated with earth sciences departments or departments with nonspecific names such as "Department of Science," while, in this case, Other is assigned to authors affiliated with mathematics, agriculture, or veterinary 
science departments, as well as to those whose departmental affiliations could not be determined.

\section{Results}

\section{Cross-Disciplinary Citation Rates}

As figure 1 shows, the CDC rates for all three disciplines generally stayed within the range of 30 percent to 45 percent over the four years studied. In comparing the three disciplines and their total citations for the four years, there was not a significant difference among the three disciplines with regard to how frequently one discipline is cited by others $\left(X^{2}=5.06\right.$, df $=2, \mathrm{p} \geq 0.05)$. Overall, CDCs to Biological Sciences and Physics decreased over time, whereas CDCs to Chemistry increased. A chi-square goodness-of-fit test was additionally performed for each discipline in an effort to determine whether changes in CDC counts from one publication year to the next were significant. These changes over time were significant for biology and physics (biology: $\mathrm{X}^{2}=10.07, \mathrm{df}=3$, $\mathrm{p} \leq 0.05$; physics: $\mathrm{X}^{2}=62.38, \mathrm{df}=3, \mathrm{p} \leq$ $0.001)$, but not for chemistry $\left(X^{2}=7.58, \mathrm{df}\right.$ $=3, \mathrm{p} \geq 0.05)$. Figure 1 , which shows the percentages of CDCs for each publication year, indicates a greater difference among the disciplines for CDCs in 2000 than in previous years, suggesting that $C D C$ rates for the three disciplines may diverge more over time.

Table 2 shows the percentage of citations from one of the three major disciplines to another. In general, these rates were quite low: most CDCs to each of the three major disciplines came not from the other two major disciplines, but from the other sciences. The one exception is the rate for biologists citing chemists: between 1995 and 2000, this rate leapt dramatically from 2.2 percent to 17.1 percent.

Because most of the CDCs came from outside the three major disciplines, we did further analysis to attempt to discern any patterns. As table 3 shows, several patterns emerged. First, the majority of

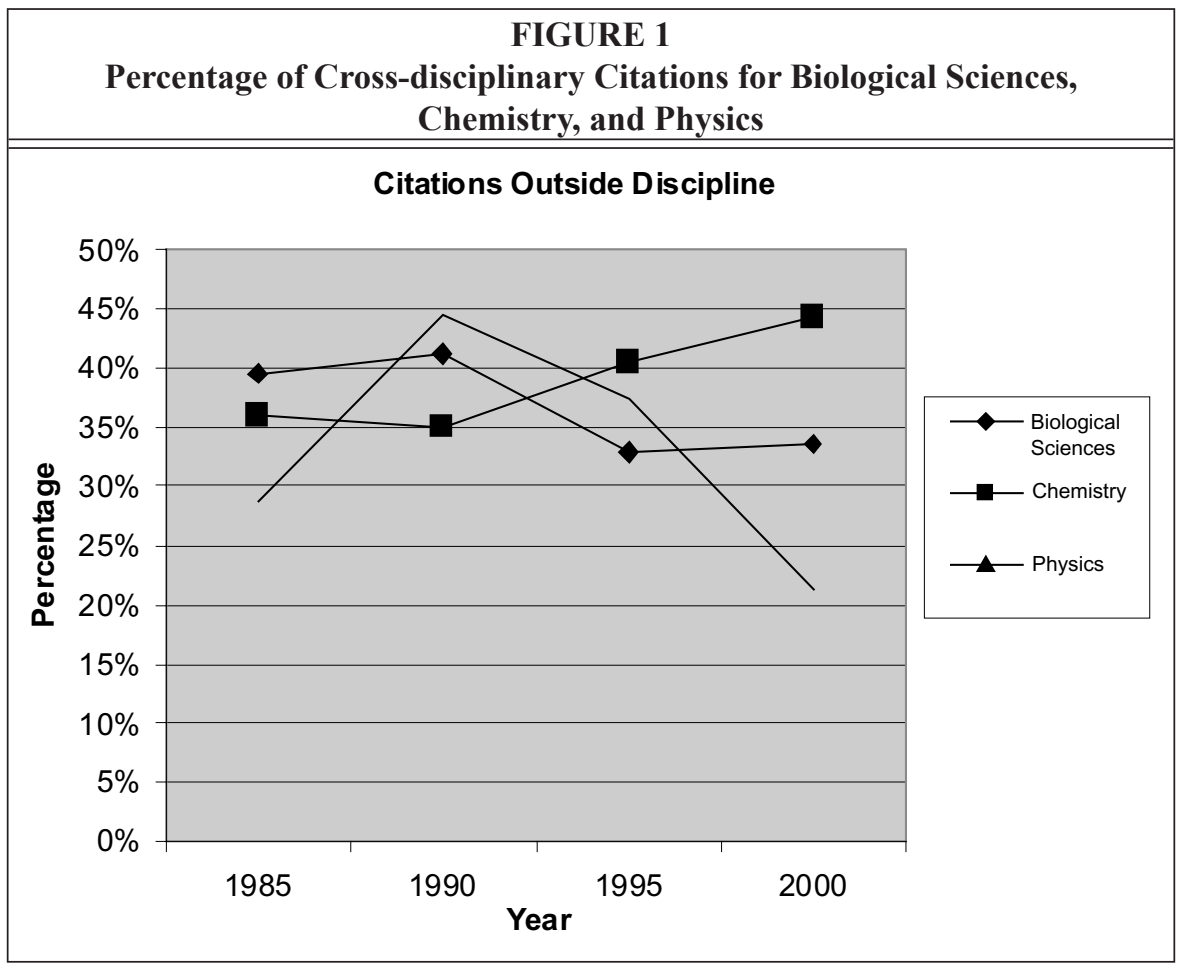




\begin{tabular}{|c|c|c|c|c|c|}
\hline \multicolumn{6}{|c|}{$\begin{array}{l}\text { TABLE } 2 \\
\text { Citations from One of the Three Major Disciplines to Another }\end{array}$} \\
\hline & Year & 1985 & 1990 & 1995 & 2000 \\
\hline \multirow{4}{*}{$\begin{array}{l}\text { Citations to Biological } \\
\text { Sciences from ... }\end{array}$} & Biological Sciences & $60.4 \%$ & $58.8 \%$ & $67.1 \%$ & $66.4 \%$ \\
\hline & Chemistry & $2.7 \%$ & $4.5 \%$ & $8.3 \%$ & $5.8 \%$ \\
\hline & Physics & $0.1 \%$ & $1.2 \%$ & $0.1 \%$ & $0.4 \%$ \\
\hline & Other Disciplines & $36.8 \%$ & $35.5 \%$ & $24.5 \%$ & $27.4 \%$ \\
\hline \multirow{4}{*}{$\begin{array}{l}\text { Citations to Chemistry } \\
\text { from ... }\end{array}$} & Biological Sciences & $7.4 \%$ & $1.7 \%$ & $2.2 \%$ & $17.1 \%$ \\
\hline & Chemistry & $64.0 \%$ & $65.0 \%$ & $59.5 \%$ & $55.6 \%$ \\
\hline & Physics & $1.9 \%$ & $8.8 \%$ & $5.0 \%$ & $2.7 \%$ \\
\hline & Other Disciplines & $26.7 \%$ & $24.5 \%$ & $33.3 \%$ & $24.6 \%$ \\
\hline \multirow[t]{4}{*}{ Citations to Physics from ... } & Biological Sciences & $0.5 \%$ & $0.2 \%$ & $1.9 \%$ & $0.3 \%$ \\
\hline & Chemistry & $1.9 \%$ & $4.4 \%$ & $5.8 \%$ & $1.6 \%$ \\
\hline & Physics & $71.3 \%$ & $55.5 \%$ & $62.7 \%$ & $78.8 \%$ \\
\hline & Other Disciplines & $26.3 \%$ & $39.9 \%$ & $29.6 \%$ & $19.3 \%$ \\
\hline
\end{tabular}

citations to Biological Sciences from other fields came mainly from Medicine for all four years studied. Nonetheless, citations from Medicine to Biological Sciences decreased steadily over the time period studied, from 21.0 percent in 1985 to 13.0 percent in 2000. Second, Engineering cited the Biological Sciences very infrequently: less than 1 percent in each of the four years.

The citations to Chemistry showed more variety. All categories cited Chemistry to some extent, although it is difficult to discern any particular patterns. The 2000 spike in citations by Biological Sciences to Chemistry articles may indicate increasing reliance on chemistry sources.

Citations to Physics articles from other science fields are dominated by citations from General Science. Authors in the "other" category tend to cite Physics somewhat more than either Biological Sciences or Chemistry. One surprising result is the 5.8 percent of citations by Medicine to Physics articles published in 1995, especially given that Medicine did not cite Physics articles at all in the other years. Additionally, in 2000, all categories except General Science cited Physics articles less than in the previous years. With 2000 being the most recent year analyzed, it would not be surprising for the number of citations to those articles to be lower in general because there has not been as much time for citations to have taken place. However, this was not the case for Biological Sciences and especially not for Chemistry, which had more citations to 2000 articles than in any of the previous years.

Figure 2 shows that the total number of citing journals in each discipline increased steadily and significantly between 1985 and 2000. This finding, combined with our rather mixed results about increasing cross-disciplinary citation, suggests that the proliferation of journal titles in the sciences in recent years is not necessarily explained by increasing interdisciplinarity.

\section{Discussion}

\section{Citations from Outside the Discipline}

Results from our study indicate that 30 percent to 45 percent of all citations to Biological Sciences, Chemistry, or Physics come from other disciplines. These 
results are strikingly different from the conclusion reached by Porter and Chubin, who reported that for articles published in selected journals in 1979, the citations between "grand categories" (for example, life sciences or physical sciences) are rare, accounting for only 4 percent of citations. ${ }^{31}$

While our overall CDC rates for the four years for Biological Sciences (36.7\%), Chemistry (39.0\%) and Physics (36.4\%) fall in a rather narrow range, the year-toyear differences suggest that cross-disciplinary usage of information changes over time. Contrary to our hypothesis, how- ever, not all of the disciplines showed an increase. Citations to Biological Sciences from other disciplines actually decreased over the time period we studied. Further analysis is needed to better understand the decline in citations to Biological Sciences. Perhaps citation analysis at the subdiscipline level or content analysis of the articles and their citations would provide more information on research trends in Biological Sciences and disciplines that cite it. Conversely, citations to Chemistry from other disciplines increased over the years analyzed. Again, a more detailed analysis of chemistry literature would

\begin{tabular}{|c|c|c|c|c|c|}
\hline \multicolumn{6}{|c|}{$\begin{array}{l}\text { Citations from Other Science Disciplines to One of the } \\
\text { Three Major Disciplines }\end{array}$} \\
\hline & Year & 1985 & 1990 & 1995 & 2000 \\
\hline \multirow{7}{*}{$\begin{array}{l}\text { Citations to Biological } \\
\text { Sciences from ... }\end{array}$} & Chemistry & $2.7 \%$ & $4.5 \%$ & $8.3 \%$ & $5.8 \%$ \\
\hline & Physics & $0.1 \%$ & $1.2 \%$ & $0.1 \%$ & $0.4 \%$ \\
\hline & Medicine & $21.0 \%$ & $17.5 \%$ & $15.7 \%$ & $13.0 \%$ \\
\hline & Engineering & $0.3 \%$ & $0.2 \%$ & $0.6 \%$ & $0.7 \%$ \\
\hline & General Science & $11.5 \%$ & $12.1 \%$ & $5.7 \%$ & $9.4 \%$ \\
\hline & Other Disciplines & $4.0 \%$ & $5.7 \%$ & $2.6 \%$ & $4.3 \%$ \\
\hline & $\begin{array}{l}\text { Total cross-disciplinary } \\
\text { citation rate }\end{array}$ & $39.6 \%$ & $41.2 \%$ & $32.9 \%$ & $33.6 \%$ \\
\hline \multirow{7}{*}{$\begin{array}{l}\text { Citations to Chemistry } \\
\text { from } \ldots\end{array}$} & Biological Sciences & $7.4 \%$ & $1.7 \%$ & $2.2 \%$ & $17.1 \%$ \\
\hline & Physics & $1.9 \%$ & $8.8 \%$ & $5.0 \%$ & $2.7 \%$ \\
\hline & Medicine & $9.9 \%$ & $3.2 \%$ & $3.8 \%$ & $7.8 \%$ \\
\hline & Engineering & $6.8 \%$ & $7.3 \%$ & $9.5 \%$ & $6.0 \%$ \\
\hline & General Science & $3.4 \%$ & $7.5 \%$ & $15.8 \%$ & $5.6 \%$ \\
\hline & Other Disciplines & $6.6 \%$ & $6.6 \%$ & $4.3 \%$ & $5.3 \%$ \\
\hline & $\begin{array}{l}\text { Total cross-disciplinary } \\
\text { citation rate }\end{array}$ & $36.0 \%$ & $35.0 \%$ & $40.5 \%$ & $44.4 \%$ \\
\hline \multirow{7}{*}{$\begin{array}{l}\text { Citations to Physics } \\
\text { from ... }\end{array}$} & Biological Sciences & $0.5 \%$ & $0.2 \%$ & $1.9 \%$ & $0.3 \%$ \\
\hline & Chemistry & $1.9 \%$ & $4.4 \%$ & $5.8 \%$ & $1.6 \%$ \\
\hline & Medicine & $0.0 \%$ & $0.0 \%$ & $5.8 \%$ & $0.0 \%$ \\
\hline & Engineering & $1.8 \%$ & $8.2 \%$ & $2.8 \%$ & $1.6 \%$ \\
\hline & General Science & $16.7 \%$ & $24.2 \%$ & $11.8 \%$ & $13.3 \%$ \\
\hline & Other Disciplines & $7.7 \%$ & $7.6 \%$ & $9.1 \%$ & $4.3 \%$ \\
\hline & $\begin{array}{l}\text { Total cross-disciplinary } \\
\text { citation rate }\end{array}$ & $28.7 \%$ & $44.5 \%$ & $37.3 \%$ & $21.2 \%$ \\
\hline
\end{tabular}




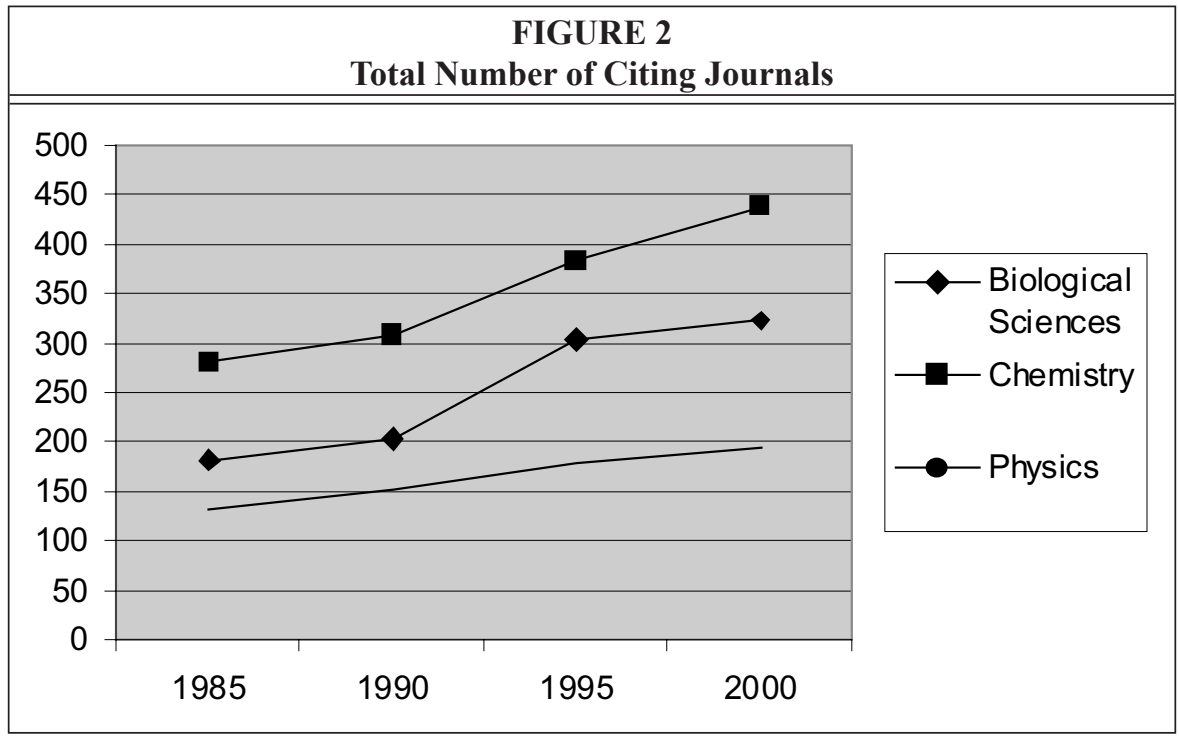

help determine whether the literatures of certain subdisciplines, such as biochemistry or physical chemistry, are increasingly cited not only by other fields such as the Biological Sciences or Physics, but also by Medicine or Chemical Engineering. Citations to Physics from other disciplines varied most widely over the four years studied, increasing sharply from 1985 to 1990 and then decreasing. It is not known why this is the case, but it would be helpful to identify research trends in the sciences that might have made articles from a certain year in a specific discipline more likely to be cited by other disciplines. Another interesting possibility proposed by Ackerson is that the "lag time" between when articles are published and when they are cited by other disciplines varies from field to field and that "the rate of diffusion is slowed between disciplines that are dissimilar." 32 Rinia et al. also suggest that "interdisciplinary impact" may not be evident until some time has passed. ${ }^{33}$ A. J. Meadows proposes that more closely related disciplines share information quickly, while the process takes longer for more unrelated disciplines. ${ }^{34}$ In other words, it could take longer than four years for other disciplines to identify and use Physics literature, which may explain why the figure for 2000 Physics articles is so much lower than that for Biological Sciences or Chemistry. This could be an important consideration in selection, weeding, and transferring decisions, to ensure that patrons will continue to have access to needed materials.

\section{Comparison with Previously Published Results}

A caveat

To test our hypothesis that the author-affiliation method of assigning discipline would yield results consistent with other researchers' findings, we compared our results to previous work in this area. For several reasons, however, it is difficult to compare the results of different studies of cross-disciplinary citation in the sciences. First, each investigation chooses and defines its disciplines differently. Some studies, like ours, take the "grand categories" of Biological Sciences, Chemistry, and Physics as their focus. Others consider the multiple subfields within a discipline, such as botany, zoology, and microbiology within the Biological Sciences. Some studies, like Earle and Vickery's, are comprehensive, studying all of science, whereas others focus exclusively on one discipline or even on one subfield. Second, meth- 


\begin{tabular}{|c|c|c|c|c|c|c|c|c|}
\hline 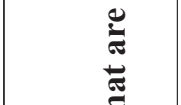 & 客高 & 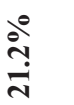 & & & & & & \\
\hline 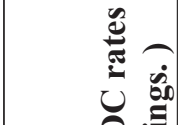 & غ̇ं & 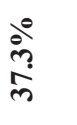 & & & & & 官 & 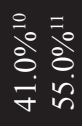 \\
\hline 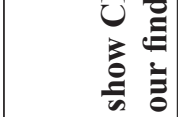 & 客完 & $\begin{array}{l}\stackrel{0}{i n} \\
\text { in } \\
\dot{y}\end{array}$ & & & & $\begin{array}{l}\text { ळे } \\
\text { in }\end{array}$ & & \\
\hline 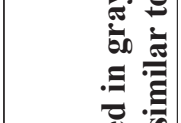 & 客㒸 & $\frac{\stackrel{9}{i}}{\stackrel{i}{i}}$ & वें & & & & & \\
\hline 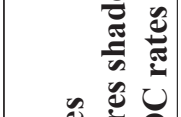 & छี่ & $\begin{array}{l}\stackrel{\circ}{+} \\
\stackrel{+}{+}\end{array}$ & & & & & & \\
\hline 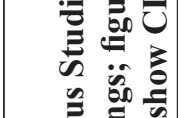 & हू் & 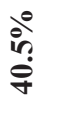 & & & & & $\frac{\dot{0}}{\dot{m}}$ & $\begin{array}{l}\stackrel{0}{0} \\
\dot{0} \\
\text { nं }\end{array}$ \\
\hline 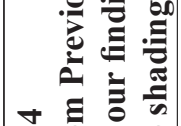 & छี่ & 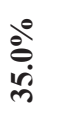 & & & & & & \\
\hline 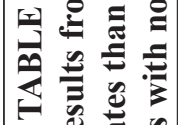 & 竎 & 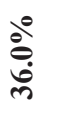 & & & & & & \\
\hline 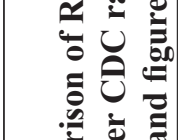 & 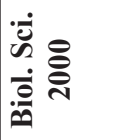 & $\begin{array}{l}\dot{b}_{0}^{0} \\
\dot{m} \\
\text { ले }\end{array}$ & & & & & & \\
\hline 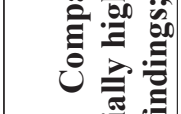 & 远 & $\begin{array}{l}\stackrel{0}{a} \\
\text { लें }\end{array}$ & & & & & $\begin{array}{l}\stackrel{0}{0} \\
0 \\
\infty \\
m\end{array}$ & $\begin{array}{l}\stackrel{0}{0} \\
\stackrel{+}{+}\end{array}$ \\
\hline 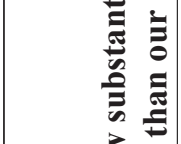 & 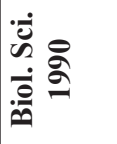 & $\stackrel{\stackrel{\oplus}{\ominus}}{\vec{\gamma}}$ & & & & & & \\
\hline 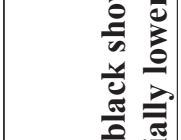 & 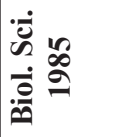 & $\begin{array}{l}\dot{b}^{\circ} \\
\text { लें }\end{array}$ & $\begin{array}{l}\stackrel{0}{*} \\
\text { in }\end{array}$ & 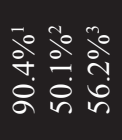 & & & & \\
\hline 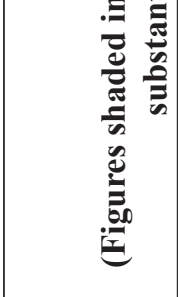 & & 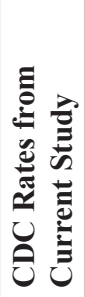 & 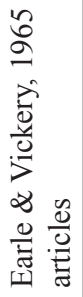 & 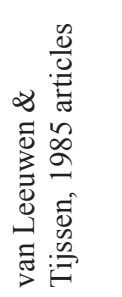 & 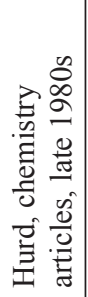 & 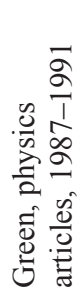 & 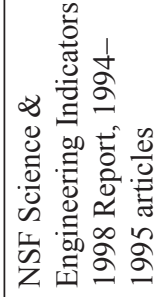 & 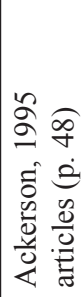 \\
\hline
\end{tabular}




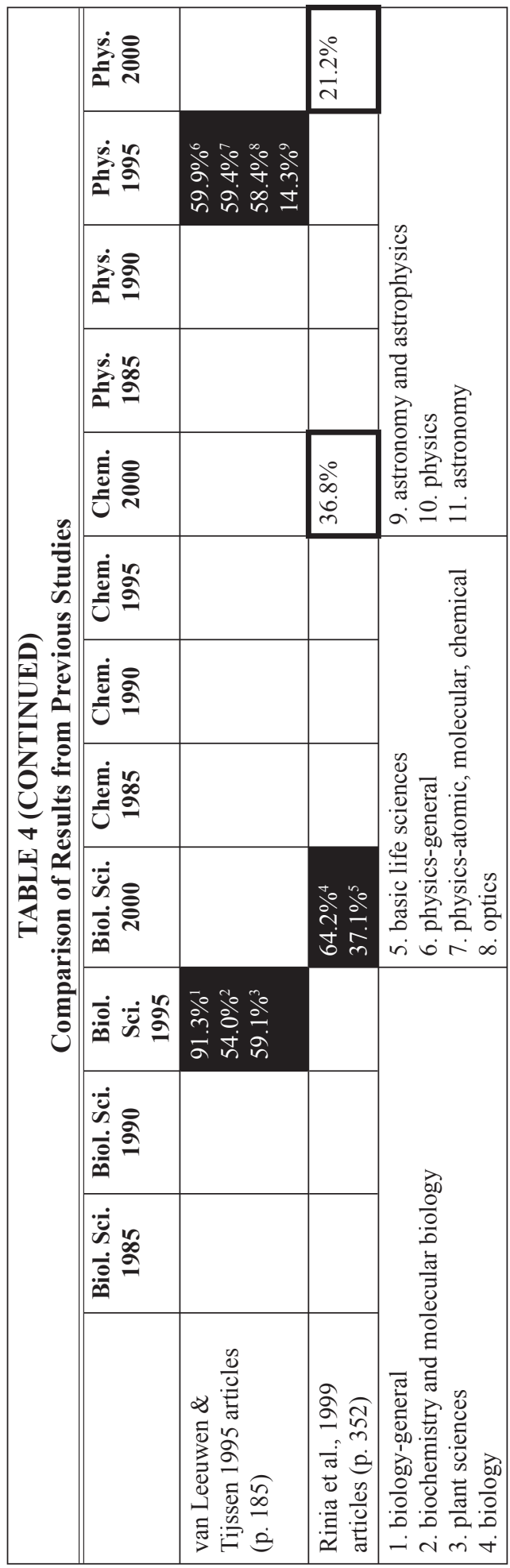

ods differ dramatically from one investigation to another. As noted above, researchers have chosen to assign discipline to articles using Dewey or LC subject headings, ISI or Ulrich's journal categories, authors' departmental affiliations, and subjects assigned by indexing services such as Chemical Abstracts. In addition, some studies focus on local collections, local use, or local authors, whereas others attempt to study larger volumes of articles, in some cases including the entire scientific literature output (for instance, Rinia et al.). Third, previous studies naturally vary by time period covered, and some seminal studies that are useful for comparison are those published in the 1960 s or earlier, which might result in dramatically differing findings, especially since interdisciplinarity is often considered to have been "born" in the 1960s.

However, we have taken measures to present the best "apples to apples" comparison between our findings and the results of previous studies (see table 4). For instance, some studies (such as Earle and Vickery's) report disciplines' "self-derivation" rates rather than $\mathrm{CDC}$ rates, so we have figured the CDC rate simply by subtracting the self-derivation rate from $100 \%$. We have also taken the liberty of aggregating disciplines in some cases to provide a more accurate comparison between another study's findings and our own. Earle and Vickery, for example, report the self-derivation rates for several subfields of Biological Sciences, but not for the discipline of Biological Sciences itself. We have aggregated their findings to enable a more fruitful comparison between their figures and our results for the Biological Sciences and for Physics. 


\section{Comparison of overall CDC rates}

Earle and Vickery's study of articles published in 1965 serves as a useful baseline for current research because their discipline coverage is comprehensive and their work provides a snapshot of citation activity in science articles for 20 years before the earliest year analyzed in our study. For the Biological Sciences, they find that 52.2 percent of citations came from outside disciplines, a somewhat higher figure than our finding of approximately 40 percent (for 1985 Biological Sciences articles). For Chemistry, the discrepancy between Earle and Vickery's findings and our own was even greater: they report a 70 percent CDC rate for Chemistry, whereas we report 36 percent. From the starting point of Earle and Vickery, then, interdisciplinary usage of articles authored by biologists or chemists appears to have decreased. For Physics, on the other hand, Earle and Vickery's results are similar to ours, with CDC rates of 24.9 percent and 28.7 percent, respectively. However, these comparisons might be somewhat distorted due to the fact that the annual number of articles published in the sciences increased so dramatically between the 1960s and the 1980s. ${ }^{35}$

In several other cases, however, results from our study resemble those of previous research. Our CDC rates of 32.9 percent and 33.6 percent for Biological Sciences articles published in 1995 and 2000, respectively, are similar to the 1998 NSF Science $\mathcal{E}$ Engineering Indicators rate of 38 percent for biology and Rinia et al.'s 37.1 percent for "basic life sciences." Our CDC rates of 40.5 percent (1995) and 44.4 percent (2000) for Chemistry articles are slightly higher than Ackerson's reported 36.0 percent (1995) and Rinia et al.'s 36.8 percent (1999). For 2000 Physics articles, our CDC rate of 21.2 percent is exactly the same as that reported by Rinia et al. Generally, results from our study and results from Ackerson and by Rinia et al. are similar; this supports our hypothesis that the author-affiliation method would produce results similar to the results of similar previous studies.
The variance in results across the research literature indicates that using similar methods of assigning discipline to scientific articles will not necessarily result in similar CDC rates. Of the seven comparison studies, four assigned discipline using ISI categories (van Leeuwen and Tijssen, Ackerson, the 1998 NSF Science and Engineering Indicators, and Rinia et al.), and the other three assigned discipline by Dewey Decimal subject (Earle \& Vickery), Ulrich's International Periodicals Directory (Hurd), and LC subject classification (Greene). The results of the four studies that use ISI categories are no more similar to each other than to the other studies' results, and there is little evidence that any one method yields more reliable results than another. This makes it difficult to evaluate our author-affiliation method: it produces results that are consistent with some, but not all, of the previously published findings.

\section{Conclusions and Implications for Collection Management}

Our results, based on an author-affiliation method of assigning discipline in the sciences, indicate decreasing CDC rates over the last 20 years for Biological Sciences and Physics, and an increasing CDC rate over the last 20 years for Chemistry. These results do not support our first hypothesis, which stated our expectation that CDC rates had increased over the time period 1985-2000.

Other studies of interdisciplinarity in the sciences use other methods to assign discipline and to measure citation rates, and their findings are not all consistent with each other or with ours. We compared our results to previous findings to test our second hypothesis, which stated our expectation that the author-affiliation method would produce results that were consistent with previous findings. However, because the previous findings are so dissimilar to each other, it is difficult to evaluate our hypothesis. Our results are consistent with some previous results, particularly other large-scale 
studies performed on articles published during the same time period that we studied, 1985-2000. But our results cannot be consistent with all previous results, simply because the previous results vary so widely. Because of the high variability among the previous results, we cannot make firm conclusions about the authoraffiliation method's validity. However, we conclude tentatively that the authoraffiliation method shows promise as an alternative to methods based on ambiguous ISI journal categories. Certainly, the author-affiliation method's results do not cohere with previous results any less than the results of other studies. Additional data from future studies may help clarify the role that this method can play in measuring cross-disciplinary citation rates.

Our results raise a few interesting questions about the methods used to measure interdisciplinarity and even about the definition of "discipline." For instance, even though our study shows an increase in interdisciplinarity in Chemistry, our Chemistry results show much less interdisciplinarity than Earle and Vickery's 1965 findings. This may show an overall trend over time toward less interdisciplinarity, as we have found for Biological Science and Physics. On the other hand, however, this apparent trend might not reflect actual levels of interdisciplinarity. It is possible that the research performed by academic departments in recent years is not rigidly defined as belonging to a particular discipline and there is more diversity of research areas within departments. Perhaps academic chemistry departments were more likely in 1985 than 1965 to include researchers who had biochemistry backgrounds. If scientists conducting research at the interface of biology and chemistry were more likely to be affiliated with biology departments in 1965, and if they often cited articles by authors affiliated with chemistry departments, it would appear that there was more interdisciplinary research going on at that time. In more recent years, however, we have noticed anecdotally that chemistry departments are likely to have scientists working on biochemistry or molecular biology research questions. As it becomes more commonplace for departments to encompass a diversity of research, assigning discipline to articles by author affiliation might lead to the conclusion that there is less cross-disciplinary usage of research from other disciplines. This is one drawback of assigning discipline to articles by author affiliation: it does not account for changes over time in the types of research areas that would be investigated in certain departments. In fact, L. L. Hargens, in his study of migration patterns of holders of scientific doctoral degrees, pointed out that "common preconceptions of the boundaries of scientific fields" may prevent researchers from fully understanding patterns of information use across discipline boundaries. ${ }^{36}$ Historical studies of academic departments and their research areas would help determine whether the research areas incorporated by departments have become more varied or interdisciplinary.

Ackerson notes that "citation analysis can be a useful tool for library decisionmaking." 37 While we agree that citation analysis can be useful, comparing our data with previous research shows that results can vary widely according to the disciplines investigated and the methods used. Our results indicate that CDC rates can change appreciably from one year to another. It is also possible that results can vary by the sample used: for instance, some studies investigate the output of one academic department at one institution, whereas others (such as Rinia et al.) look at the entire scientific literature produced in selected years. Our sample, consisting of articles published by scientists at Big 12 institutions, falls in the middle with regard to sample size and scope, but it is possible that the scientific output of scientists at Big 12 universities is not representative of the scientific output as a whole. 
Fortunately, for the purposes of collection management, it may not be necessary to know the exact CDC rates for disciplines. It may be enough to know that at least one-third to one-half of the literature cited by one discipline belongs to another discipline, so other departments will be affected by decisions that are made regarding one department's subscriptions, cancellations, or transfers.

Hurd also discusses the implications of cross-disciplinary use of information for the physical arrangements of libraries. She claims that such usage might be better supported by a broader science library, rather than smaller branches that focus on a small number of specific disciplines. ${ }^{38}$ Leon Shkolnik points out that the increasing availability of information sources in electronic formats may to some degree alleviate the inconvenience of having to retrieve items from multiple branch libraries, but some materials, particularly older ones, are still available to users only in print. ${ }^{39}$ Therefore, the potential for interdisciplinary usage of information should be considered in both the physical arrangement of libraries and the arrangement of electronic resources.

It is all too easy for information professionals who are responsible for collection development and collection management in specific disciplines to focus exclusively on those disciplines. However, we will serve all of our patrons better if we remember how frequently researchers from other disciplines make use of those materials as well.

\section{Notes}

1. Rustom Roy, "Interdisciplinary Science on Campus - The Elusive Dream." Chemical and Engineering News 55 (1977): 28-40.

2. Fernanda Morillo, María Bordons, and Isabel Gómez, "An Approach to Interdisciplinarity through Bibliometric Indicators," Scientometrics 51, no. 1 (2001): 203-22; Fernanda Morillo, María Bordons and Isabel Gómez, "Interdisciplinarity in Science: A Tentative Typology of Disciplines and Research Areas," Journal of the American Society for Information Science and Technology 54, no. 13 (2003): 1237-49; Luis Sanz-Menéndez, María Bordons, and M. Angeles Zulueta, "Interdisciplinarity as a Multidimensional Concept: Its Measure in Three Different Research Areas," Research Evaluation 10, no. 1 (2001): 47-58; Joachim Schummer, "Multidisciplinarity, Interdisciplinarity, and Patterns of Research Collaboration in Nanoscience and Nanotechnology," Scientometrics 59, no. 3 (2004): 425-65; Pedro Alvarez and Antonio Pulgarín, "The Rasch Model. Measuring the Impact of Scientific Journals: Analytical Chemistry," Journal of the American Society for Information Science 47, no. 6 (1996): 458-67.

3. W. Glänzel, A. Schubert, and H.-J. Czerwon, "An Item-by-Item Subject Classification of Papers Published in Multidisciplinary and General Journals Using Reference Analysis," Scientometrics 44, no. 3 (1999): 427.

4. Morillo et al., "Interdisciplinarity in Science," 1239.

5. Sydney J. Pierce, "Boundary Crossing in Research Literatures as a Means of Interdisciplinary Information Transfer," Journal of the American Society for Information Science 50, no. 3 (1999): $271-79$.

6. Liwen Qiu, "A Study of Interdisciplinary Research Collaboration," Research Evaluation 2 (1992): 169-75.

7. Schummer, "Multidisciplinarity, Interdisciplinarity, and Patterns of Research Collaboration in Nanoscience and Nanotechnology," 425-65.

8. John W. Houghton, Colin Steele, and Margaret Henty, Changing Research Practices in the Digital Information and Communication Environment (Canberra, Australia: Department of Education, Science, and Training, 2003), 39.

9. National Science Foundation, Grant Proposal Guide (Arlington, Va.: National Science Foundation, 2004), 39.

10. National Science Foundation, Science \& Engineering Indicators (Washington, D.C.: National Science Foundation, 2004), chap. 5, p. 43.

11. Ibid., chap. 5 , p. 37.

12. Jin M. Choi, "Citation Analysis of Intra- and Interdisciplinary Communication Patterns of Anthropology in the U.S.A.," Behavioral \& Social Sciences Librarian 6, nos. 3-4 (1988): 65-84; Sherri Edwards, "Citation Analysis as a Collection Development Tool: Theses and Dissertations," Serials 


\section{Tracking Cross-Disciplinary Information Use by Author Affiliation 461}

Review 25, no. 1 (1999): 11-20; Jean-Pierre V. M. Herubel and Anne L. Buchanan, “Jean-Jacques Rousseau among the Footnotes: Mapping Interdisciplinary Research in Social Science Citation Index," Behavioral \& Social Sciences Librarian 13, no. 1 (1994): 49-57; Yves J. Khawam, "The AI Interdisciplinary Context: Single or Multiple Research Bases?" Library E Information Science Research 14, no. 1 (1992): 57-74; Katherine W. McCain, "Cross-Disciplinary Citation Patterns in the History of Technology," Proceedings of the American Society for Information Science Annual Meeting 23 (1986): 194-98; Katherine W. McCain, "Core Journal Networks and Cocitation Maps in the Marine Sciences: Tools for Information Management in Interdisciplinary Research," Proceedings of the American Society for Information Science Annual Meeting 29 (1992): 3-7; Daniel E. Morse and Kenneth H. Nealson, "Interdisciplinary Research at the Nation's Coastal Laboratories," Biological Bulletin 190, no. 2 (1996): 260-68; Schummer, "Multidisciplinarity, Interdisciplinarity, and Patterns of Research Collaboration in Nanoscience and Nanotechnology"; Thomas W. Steele and Jeffrey C. Stier, "The Impact of Interdisciplinary Research in the Environmental Sciences: A Forestry Case Study," Journal of the American Society for Information Science 51, no. 5 (2000): 476-84; William H. Walters and Esther I. Wilder, "Bibliographic Index Coverage of a Multidisciplinary Field," Journal of the American Society for Information Science and Technology 54, no. 14 (2003): 1305-12.

13. Cynthia Dobson, Jeffrey D. Kushkowski, and Kristin H. Gerhard, "Collection Evaluation for Interdisciplinary Fields: A Comprehensive Approach," The Journal of Academic Librarianship 22, no.4 (1996): 279-84; Kristin H. Gerhard, "Challenges in Electronic Collection Building in Interdisciplinary Studies," Collection Management 25, nos. 1-2 (2000): 51-65; Janet Hughes, "Use of Faculty Publication Lists and ISI Citation Data to Identify a Core List of Journals with Local Importance," Library Acquisitions: Practice \& Theory 19, no. 4 (1995): 403-13; Jeffrey D. Kushkowski, Kristin H. Gerhard, and Cynthia Dobson, "A Method for Building Core Journal Lists in Interdisciplinary Subject Areas," Journal of Documentation 54, no. 4 (1998): 477-88; Katherine W. McCain, "Biotechnology in Context: A Database-Filtering Approach to Identifying Core and Productive Non-Core Journals Supporting Multidisciplinary R \& D," Journal of the American Society for Information Science 46, no. 4 (1995): 306-17.

14. L. L. Hargens, "Migration Patterns of U.S. Ph.D.s among Disciplines and Specialties," Scientometrics 9, nos. 3-4 (1986): 145-64; Katherine W. McCain, "Core Journal Networks and Cocitation Maps: New Bibliometric Tools for Serials Research and Management," Library Quarterly 61, no. 3 (1991): 311-36.

15. Penelope Earle and Brian Vickery, "Subject Relations in Science/Technology Literature," ASLIB Proceedings 21, no. 6 (1969): 237-43.

16. A. L. Porter and D. E. Chubin, "An Indicator of Cross-Disciplinary Research," Scientometrics 8, nos. 3-4 (1985): 161-76.

17. Morillo et al., "An Approach to Interdisciplinarity through Bibliometric Indicators"; Morillo et al., "Interdisciplinarity in Science"; Sanz-Menéndez et al., "Interdisciplinarity as a Multidimensional Concept"; Schummer, "Multidisciplinarity, Interdisciplinarity, and Patterns of Research Collaboration in Nanoscience and Nanotechnology"; Alvarez and Pulgarín, "The Rasch Model."

18. Choi, "Citation Analysis of Intra- and Interdisciplinary Communication Patterns of Anthropology in the U.S.A."

19. Morillo et al., "An Approach to Interdisciplinarity through Bibliometric Indicators."

20. Pierce, "Boundary Crossing in Research Literatures as a Means of Interdisciplinary Information Transfer," 272.

21. Ed J. Rinia, Thed N. van Leeuwen, Eppo E. W. Bruins, Hendrik G. van Vuren, and Anthony F.J. van Raan, "Measuring Knowledge Transfer between Fields of Science," Scientometrics 54, no. 3 (2002): 347-62.

22. Schummer, "Multidisciplinarity, Interdisciplinarity, and Patterns of Research Collaboration in Nanoscience and Nanotechnology," 436.

23. National Science Foundation, Science and Engineering Indicators (Arlington, Va.: National Science Foundation, 1998), chap. 5, p. 39 and Appendix, Table 5-48.

24. Thed van Leeuwen and Robert Tijssen, "Interdisciplinary Dynamics of Modern Science: Analysis of Cross-Disciplinary Citation Flows," Research Evaluation 9, no. 3 (2000): 183-87.

25. W. Glänzel, A. Schubert, and H.-J. Czerwon, "An Item-by-Item Subject Classification of Papers Published in Multidisciplinary and General Journals Using Reference Analysis," Scientometrics 44, no. 3 (1999): 427-39.

26. Morillo et al., "Interdisciplinarity in Science."

27. Qiu, "A Study of Interdisciplinary Research Collaboration."

28. Julie M. Hurd, "Interdisciplinary Research in the Sciences: Implications for Library Organization," College E Research Libraries 53, no. 3 (1992): 283-97.

29. Julie M. Hurd, Deborah D. Blecic, and Rama Vishwanatham, "Information Use by Molecular Biologists: Implications for Library Collections and Services," College E Research Libraries 60, no. 
1 (1999): 31-43.

30. Linda G. Ackerson and Karen Chapman, "Identifying the Role of Multidisciplinary Journals in Scientific Research," College \& Research Libraries 64, no. 6 (2003): 471.

31. Porter and Chubin, "An Indicator of Cross-Disciplinary Research," 165.

32. Linda G. Ackerson, "Visualizing the Configuration of Scientific Literature: A Study of Disciplinary Relationships," Reference \& User Services Quarterly 39, no. 1 (Fall 1999): 49-50.

33. Rinia et al., "Measuring Knowledge Transfer between Fields of Science," 349.

34. A. J. Meadows, "Diffusion of Information across the Sciences," Interdisciplinary Science Reviews 1, no. 3 (1976): 259.

35. Donald W. King, Dennis D. McDonald, and Nancy K. Roderer, Scientific Journals in the United States: Their Production, Use, and Economics, Publications in the Information Sciences, consulting editor Rita G. Lerner (Stroudsburg, PA: Hutchinson Ross Publishing Co., 1981): 60; Carol Tenopir and Donald W. King, Towards Electronic Journals: Realities for Scientists, Librarians, and Publishers (Washington, D.C.: Special Libraries Association, 2000): 242.

36. Hargens, "Migration Patterns of U.S. Ph.D.s among Disciplines and Specialties," 146.

37. Linda G. Ackerson, "Visualizing the Configuration of Scientific Literature."

38. Hurd, "Interdisciplinary Research in the Sciences," 295.

39. Leon Shkolnik, "The Continuing Debate over Academic Branch Libraries," College \& Research Libraries 52, no. 4 (1991): 349.

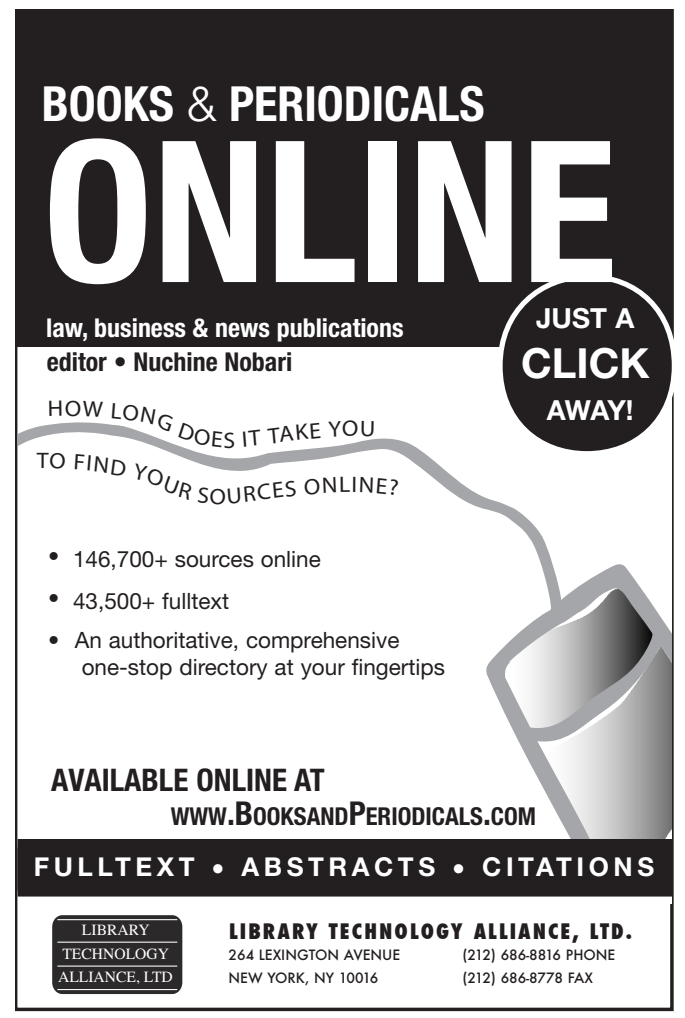

